\title{
Examining the Effects of Workstation Design Satisfaction, Computer Usage, Supervisory and Co-worker Support on Perceived Physical Discomfort and Psychosocial Factors
}

\author{
Michelle Robertson ${ }^{1}$, Emily Huang ${ }^{1}$, and Nancy Larson ${ }^{2}$ \\ ${ }^{1}$ Liberty Mutual Research Institute for Safety, Hopkinton, MA \\ ${ }^{2} 3 \mathrm{M}$ Corporation, Minnesota, MN
}

\begin{abstract}
This study examined the factors of computer use, job tasks, musculoskeletal and visual discomfort and organizational support to better understand the magnitude of their impact on the safety and health of computer work employees. A cross-sectional survey was administered to a large manufacturing company to investigate these relationships. Associations between these study variables were tested along with moderating effects framed within a conceptual model. Significant relationships were found between discomfort, computer use and psychosocial factors including supervisory relations moderating the relationships between workstation satisfaction and visual and musculoskeletal discomfort. This study provides guidance for developing recommendations in designing office ergonomic interventions with the goal of reducing musculoskeletal and visual discomforts while enhancing worker performance and their quality of worklife.
\end{abstract}

Keywords: Office ergonomics, computer workers, psychosocial factors, discomfort.

\section{Introduction}

The occurrence of Work-Related Musculoskeletal Disorders (WMSDs) and visual discomfort in computer workers continues to be of concern. Musculoskeletal disorders (WMSDs) in the US resulted in 375,540 occupational injury and illness cases involving days away from work (annual incidence rate 68.8 cases per 10,000 full time workers, accounted for $30 \%$ of total injury cases for 2005), and its prevalence is high among computer users (often 40 to 80\%) [1-3]. Computer work is identified as a risk factor for WMSDs and visual discomfort in the working age population [4-6]. Upper extremity musculoskeletal symptoms among computer users are reported to be as high as $63 \%$ [4]. Critical computer and office work characteristics that have been found to be associated with WMSDs and visual discomfort are: workstation design, psychosocial factors, and daily hours working on a computer [7-10].

This study examines the relationships among the factors of satisfaction level regarding workstation design, computer use, relationships with co-workers and supervisors, 
and various perceived musculoskeletal and visual discomfort levels (i.e., head, eyestrain, upper body, lower body and overall discomfort). Figure 1 presents the conceptual model for this study. These results would provide guidance in developing recommendations for designing office ergonomic interventions with the goal of reducing musculoskeletal and visual discomforts among intensive computer users as well as improving the overall safety of workers.

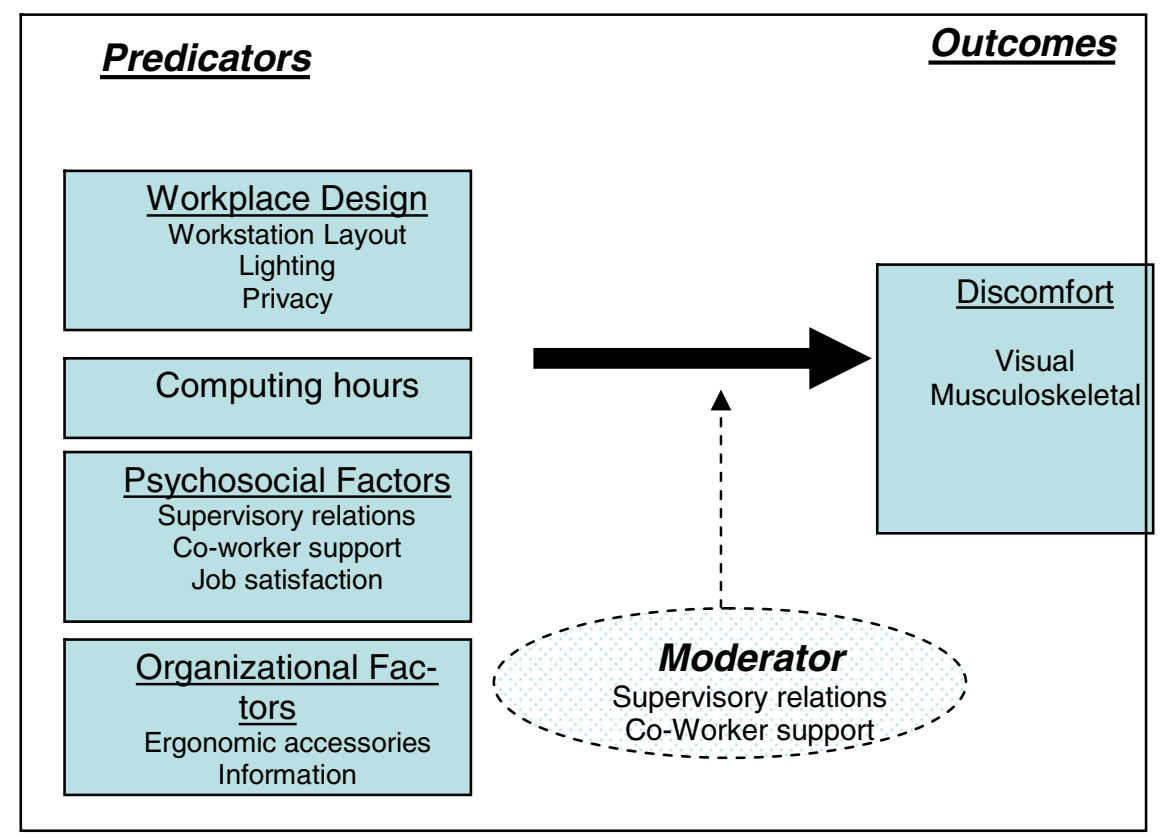

Fig. 1. Conceptual Model of the Study

\section{Methods}

\subsection{Study Site}

We conducted this study at a large U.S. manufacturing corporation whose offices consisted of multiple buildings, fairly similar in environmental design, workstation size, and workspace. There were differences, however, with regard to furniture and the computer tasks. The main computer tasks were word processing, data entry, and spreadsheet work. A few employees worked in design and used Computer Aided Design (CAD) computer equipment. The majority of workstations were not adjustable. There was a wide variety of chair styles and range of adjustability (a minimum of 3 adjustments). All employees had access to ergonomics information, accessory tools or, upon request, an individual ergonomics workstation evaluation. 


\subsection{Study Design}

After approval by the Institutional Review Committee for Human Subjects, we administered a cross-sectional survey to a randomly selected sample of office computer users during work hours via Lotus Notes. An announcement about the study was made by the company's ergonomics manager. The survey was distributed to $20 \%$ of the company's population for a total distribution of 3,400 surveys.

\subsection{Survey Design}

The computer ergonomics survey was based on several previously validated computer ergonomics and discomfort questionnaires (11-12). The survey consisted of 52 items grouped in eight general categories. The first category consisted of demographic items: individual division, department, location, job categories (i.e., assistant, analyst, customer service, engineer, sales, staff, researcher, supervisor), tenure, gender and age. The other seven categories included self-reported perceptions of: (1) workstation design/layout (work surface area, surface height, storage space, privacy appearance, chair, lighting, glare); (2) organizational issues, (e.g., obtaining ergonomic accessories, information and assistance); (3) musculoskeletal discomfort (neck, shoulder, elbow, wrist/hand, upper back, low back, hip, knee, ankle/foot); (4) visual discomfort (headaches and eyestrain/vision); (5) psychosocial issues (co-worker support, job satisfaction, supervisory relations); (6) workload and computer use (hours at work, hours at home, time sitting); and (7) job tasks (mousing/keying, telephone, handwriting, meetings, office machine use, filing).

Respondents evaluated workstation design by rating satisfaction of eight workstation design features questions with 3-point Likert-type scales. Organizational issues were evaluated through questions on ease of obtaining ergonomics accessories, and accessible ergonomic information. Overall self-reported musculoskeletal discomfort experienced in the past three months was rated by responding to a Yes/No question. Additionally, musculoskeletal work-related discomfort was assessed for 9 different body parts and visual discomfort was assessed for 2 items (headache and eyestrain). Frequency and severity of symptoms during the preceding 3 months were evaluated using 5-point Likert-type scales. Productivity, as it relates to how often the discomfort interfered with the ability to perform the job, was rated with 5-point Likert-type scales for each of the 9 body parts and 2 visual items. Co-worker support was evaluated through five questions and was rated by a 3-Point Likert-type scale. Job satisfaction and supervisory support were evaluated through 2 questions and were rated by 3-point Likert-type scales.

Questions on workload, computer use and job tasks were rated by total computer use time, including computer work done both at work and at a home.

\subsection{Data Analyses}

Characteristics of the study population were summarized using relative frequency distributions and other descriptive statistics. Tests of bivariate associations were conducted to assess the relationships between the study variables. A series of multiple regressions were conducted to examine the effects of the predicators variables on the outcomes variables of visual and musculoskeletal discomfort as well as the moderating 
effects of supervisory relations and co-worker support. For the outcome variable of discomfort we created four composite scores of visual (1) and musculoskeletal discomfort (3) to be used in the testing of the model for overall visual and musculoskeletal discomfort.

\section{Results}

\subsection{Participants}

There was a response rate of $37 \%$, where 1,259 surveys were completed. Of the survey respondents, $55 \%$ were male. There were nine job categories identified and the administration category represented the largest number of individuals (46\%).

\subsection{Musculoskeletal and Visual Discomfort}

The survey findings revealed that for all job categories, the most frequent discomforts reported at least monthly were: eye strain (48\%), neck pain $(43 \%)$, headaches $(45 \%)$, shoulder pain $(40 \%)$, wrist pain $(36 \%)$, and low back pain $(35 \%)$.

Fifty seven percent of respondents reported experiencing discomfort while performing their job during the past three months, responding to a Yes/No question. Reporting discomfort over the past 3 months was positively correlated with more individual frequent reports of discomfort for all body parts: neck $(r=.34)$, shoulder $(r=.33)$, elbows $(\mathrm{r}=.28)$, wrists $(\mathrm{r}=.38)$, upper back $(\mathrm{r}=.29)$, lower back $(\mathrm{r}=.27)$, hip $(\mathrm{r}=.16)$, knee, $(\mathrm{r}=.13)$, and ankle $(\mathrm{r}=.13)$ as well as for headaches $(\mathrm{r}=.23)$ and eyestrain $(\mathrm{r}=.27)$ [all sig. at .01 level].

\subsection{Computer Use and Musculoskeletal Discomfort}

Seventy percent of the respondents reported spending four or more hours using the computer each day at work. Moreover, $35 \%$ of employees reported spending six or more hours using the computer each day at work. Participants in sales reported the highest percentage $(67 \%)$ of overall musculoskeletal discomfort while performing their job, followed by analysts (64\%), then assistants (58\%).

Significant positive associations were found for all visual and body part discomfort frequency levels and the number of working computer hours. The correlation coefficients were: $\mathrm{r}=.18$ (headache), $\mathrm{r}=.23$ (eye strain), $\mathrm{r}=.19$ (neck pain), $\mathrm{r}=.18$ (shoulder pain), $\mathrm{r}=.13$ (elbow pain), $\mathrm{r}=.15$ (wrist pain), $\mathrm{r}=.18$ (upper back pain), $\mathrm{r}=.13$ (lower back pain), $\mathrm{r}=.15$ (hip pain), $\mathrm{r}=.15$ (knee pain), $\mathrm{r}=.08$ (ankle pain) all significant at the .01 level.

\subsection{Ergonomics Accessories and Musculoskeletal and Visual Discomfort}

A significant negative correlation between obtaining ergonomic accessories and overall musculoskeletal discomfort $(\mathrm{r}=-.18, \mathrm{p}<.01)$ was revealed. That is, the easier it was to obtain ergonomic accessories, the less frequently participants reported musculoskeletal discomfort over the three-month period. Further, significantly negative correlations were found between ease of obtaining ergonomic accessories and frequency 
of discomfort: headache $(\mathrm{r}=-.07)$, eye strain $(\mathrm{r}=-.10)$, neck pain $(\mathrm{r}=-.10)$, shoulder pain $(r=.06)$, elbow pain, $(r=-.08)$, wrists pain, $(r=-.11)$, lower back pain, $(r=-.10)$, knee pain $(r=-.06)$, [all p's <.05]. Additionally, the finding that the more satisfied the respondent was with the workstation, the easier it was for them to obtain ergonomic accessories was positively significant $(\mathrm{r}=.27, \mathrm{p}<.01)$.

A significant negative correlation was found between knowing how to request an ergonomic evaluation and less frequently reported musculoskeletal discomfort over the past 3 months $(\mathrm{r}=-.11, \mathrm{p}<.01)$.

\subsection{Work Environment Design}

Only half the respondents reported making appropriate changes to their workstations or work habits to address their discomfort. Participants who did make changes to address their discomfort were associated with significantly less frequent discomfort over the prior 3 months $(\mathrm{r}=.21, \mathrm{p}<.01)$.

\subsection{Relationships among the Predicators and Outcomes}

Predicators effects. The results from the multiple regressions showed that gender (being female), lower satisfaction level with the workstation design, higher number of hours of daily computer use, and poor relationships with co-workers and supervisors had significant effects on employees' various self-reported musculoskeletal and visual discomfort levels (all p's <.05).

Moderating effects. The psychosocial factor of supervisory relations partially moderated the relationships between satisfaction of workstation design and work environment lighting, as well as the number of hours of computer use on various musculoskeletal and visual discomfort levels $(\mathrm{p}<.05)$.

\section{Conclusion}

This study investigated the factors of computer use, musculoskeletal and visual discomfort and organizational support to more fully understand the impact of computer work on workers. Moreover, the moderating roles of supervisory support and coworker support were examined. This study identified potential areas for designing office ergonomics interventions concerning workstation design, psychosocial issues, computer use, and organizational response.

Limitations of this study should be considered since these are baseline results representing a cross-sectional survey. Thus, temporal relationship between discomfort and the other study variables cannot be established. These study outcomes consisted of self-reported symptomatology which may not be a stable indicator of musculoskeletal disorder in the working population [6]. However, Hunting et al. [13] found that approximately one third of employees with complaints also had clinical findings associated with high muscle and tendon strain, suggesting that symptoms may be a sensitive indicator of musculoskeletal disorders.

Results of this study provide supporting and consistent evidence that musculoskeletal and visual discomforts of computer users are associated with a variety of 
physical, psychosocial and organizational factors such as working hours, job tasks, computer use, supervisory and co-worker support and ergonomics assistance [4-10]. These factors are to be considered as key indicators in designing and implementing corporate office ergonomics interventions [14-21] with the goal of reducing WMSDs and visual discomfort while enhancing worker performance and the safety of computer and office workers.

\section{References}

1. Katz, J.N., Amick, B.C., Carroll, B.B., Hollis, C., Fossel, A.H., Coley, C.M.: Prevalence of upper extremity musculoskeletal disorders in college students. Am. J. Med. 109(7), 586-588 (2000)

2. Schlossberg, E.B., Morrow, S., Llosa, A.E., Mamary, E., Dietrich, P., Rempel, D.M.: Upper extremity pain and computer use among engineering graduate students. Am. J. Ind. Med. 46(3), 297-303 (2004)

3. Zapata, A.L., Moraes, A.J., Leone, C., Doria-Filho, U., Silva, C.A.: Pain and musculoskeletal pain syndromes related to computer and video game use in adolescents. Eur. J. Pediatr. 165(6), 408-414 (1994)

4. Bernard, B., Sauter, S., Fine, L., Petersen, M., Hales, T.: Job task and psychosocial risk factors for work-related musculoskeletal disorders among newspaper employees. Scand. J. Work Environ. Health 20, 417-426 (1994)

5. Bergqvist, U., Wolgast, E., Nilsson, B., Voss, M.: Musculoskeletal disorders among visual display terminal workers: individual, ergonomic, and workorganizational factors. Ergonomics 38, 763-776 (1995)

6. Marcus, M., Gerr, F.: Upper extremity musculoskeletal symptoms among female office workers: associations with video display terminal use and occupational psychosocial stressors. Am. J. Ind. Med. 29, 161-170 (1997)

7. Hales, T.R., Sauter, S.L., Peterson, M.R., et al.: Musculoskeletal disorders among visual display terminal users in a telecommunications company. Ergonomics 37, 1603-1621 (1994)

8. Faucett, J., Rempel, D.: VDT-related musculoskeletal symptoms: interactions between work posture and psychosocial work factors. Am. J. Ind. Med. 26, 597-612 (1994)

9. Sauter, S.L., Schleifer, L.M., Knutson, S.: Work posture, workstation design, and musculoskeletal discomfort in a VDT data entry task. Hum. Factors 33, 151-167 (1991)

10. Demure, B., Luippold, R.S., Bigelow, C., Ali, D., Mundt, K., Liese, B.: Video display terminal workstation improvement program: I. Baseline associations between musculoskeletal discomfort and ergonomic features of workstations. J. Occup. Environ. Med. 42 (2000)

11. Caplan, R.D., Cobb, S., French, J.R., Harrison, R.V., Pinneau, S.R.: Job Demands and Worker Health, U.S. Government Printing, Washington, DC (1975)

12. Brill, M., Margulis, S., Konar, E.: Using Office Designs to Increase Productivity. Westinghouse Furniture Systems, New York (1984)

13. Bergqvist, U.O., Voss, M., Wibom, R.: A longitudinal study of VDT work and health. Int. J. Human-Computer Interaction 4, 197-219 (1992)

14. Hunting, W., Laubli, T., Grandjean, E.: Postural and visual loads at VDT workplaces. I. Constrained postures. Ergonomics 24, 917-931 (1981)

15. Knave, B.G., Wibom, R.I., Voss, M., Hedstrom, L.D., Bergqvist, U.O.: Work with video display terminals among office employees. I. Subjective symptoms and discomfort. Scand. J. Work Environ. Health 11, 457-466 (1998) 
16. Daum, K.M., Clore, K.A., Simms, S.S., et al.: Productivity associated with visual staring among computer users. Optometry 75, 33-47 (2004)

17. Brisson, C., Montreuil, S., Punnett, L.: Effects of an ergonomic training program on workers with video display units. Scand. J. Work Environ. Health 25, 255-263 (1999)

18. Bayeh, A.D., Smith, M.J.: Effect of physical ergonomics on VDT workers' health: A longitudinal intervention field study in a service organization. International Journal of $\mathrm{Hu}$ man-Computer Interaction 11, 109-135 (1991)

19. Aaras, A., Horgen, G., Bjorset, H., et al.: Musculoskeletal, visual and psychosocial stress in VDU operators before and after multidisciplinary ergonomic interventions. Appl. Ergon. 29, 335-354 (1998)

20. Robertson, M.M., Huang, Y.H., Schliefier, L., O’Neill, M.: Applied Ergonomics. Flexible workspace design and ergonomics training: Impacts on the psychosocial work environment, musculoskeletal health, and work effectiveness among knowledge workers, Applied Ergonomics 39, 482-494 (2008)

21. Robertson, M.M., Amick, B., Bazzani, L., DeRango, K., Rooney, T., Harrist, R., Moore, A.: The effects of an office ergonomics training and chair intervention on worker knowledge, behavior and musculoskeletal risk. Applied Ergonomics, 124-135 (2009)

22. Henning, R.A., Jacques, P., Kissel, G.V., Sullivan, A.B., Alteras-Webb, S.M.: Frequent short rest breaks from computer work: effects on productivity and well-being at two field sites. Ergonomics 40, 78-91 (1997) 